\title{
Development and use of a new burner rig facility to mimic service loading conditions of Ni-based single crystal superalloys
}

\author{
Florent Mauget ${ }^{1, \text { a }}$, Damien Marchand ${ }^{1}$, Guillaume Benoit ${ }^{1}$, Médéric Morisset ${ }^{1}$, Denis Bertheau ${ }^{1}$, Jonathan Cormier ${ }^{1}$, \\ José Mendez $^{1}$, Zéline Hervier ${ }^{2}$, Elisabeth Ostoja-Kuczynski ${ }^{2}$, and Clara Moriconi ${ }^{2}$ \\ ${ }^{1}$ Institut Pprime, CNRS, ENSMA, Université de Poitiers, UPR CNRS 3346, Physics and Mechanics of Materials \\ Department, ENSMA, Téléport 2, 1 avenue Clément Ader, BP. 40109, 86961 Futuroscope Chasseneuil Cedex, France \\ ${ }^{2}$ Safran - Turbomeca, Avenue Joseph Szydlowski, 64511 Bordes Cedex, France
}

\begin{abstract}
Performing representative experiments of in-service operating conditions of Ni-based superalloys used as high pressure turbine blades in aeroengines is a challenging issue due to the complex environmental, mechanical and thermal solicitations encountered by those components. A new burner rig test facility called MAATRE (French acronym for Mechanics and Aerothermics of Cooled Turbine Blades) has been developed at ENSMA - Pprime Institute to mimic as close as possible those operating conditions. This new test bench has been used to perform complex non-isothermal creep tests representative of thermomechanical solicitations seen by some sections of HP turbine blades during engine certification procedure.
\end{abstract}

\section{Introduction}

Nickel-based single crystal superalloys are today widely used materials for the design of the high-pressure (HP) turbine blades and vanes of industrial gas turbines, aeroengines and turboshaft engines for helicopters. Many studies in the open literature have been devoted to the characterization of the mechanical behaviour and the damage mechanisms of this type of materials under various kind of tests (creep, low cycle fatigue, tension tests) [1,2]. Standard laboratory tests, such as isothermal creep tests and isothermal tensile tests are today widely used to identify most of the mechanical properties of single crystals. All those mechanical characterizations are used as inputs for the identification of lifing methodologies for these above-mentioned components. Nevertheless, inservice loading paths seen by HP turbine blades are very complex and very far from the isothermal conditions encountered during common laboratory tests.

For this reason, a new burner rig facility (the MAATRE burner) able to reproduce complex thermomechanical conditions has been developed and is now operating in Pprime institute. It has been designed to reproduce turboreactors operating conditions with a good control of both the applied temperature and mechanical loading coupled with a monitoring of the samples deformations.

In this context, the aim of this article is to illustrate some capabilities of this equipment and some new issues related to such close-to-reality testing procedures. The first part will be devoted to the working principle of this burner rig. The second one will detail two non-isothermal creep tests representative of certification procedures of

\footnotetext{
${ }^{a}$ Corresponding author: florent.mauget@ensma.fr
}

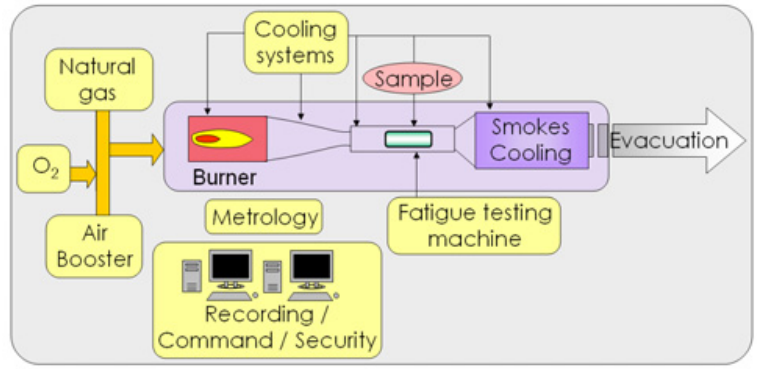

Figure 1. Working principle of the MAATRE test bench.

helicopter turbines. The last part will be dedicated to a validation of the creep elongation under such nonisothermal conditions using the Polystar model [3,4].

\section{Working principle}

A schematic description of MAATRE test bench is presented in Fig. 1.

As observed in Fig. 1, a burner based on the combustion of natural gas with air supplies hot gases which are blown on the sample lying in the testing section. To reach higher temperatures for some very specific conditions, the combustion could be doped with oxygen. Those hot gases are accelerated using a convergent located in the exhaust section of the burner, hence allowing a sufficient gas velocity in the testing section and subsequent sufficiently high heat exchanges at the samples surface to allow very fast heating and cooling rates. Samples are also mechanically loaded (under monotonic or cyclic loading paths) with an electromechanic testing machine or

This is an Open Access article distributed under the terms of the Creative Commons Attribution License 4.0, which permits unrestricted use, distribution, and reproduction in any medium, provided the original work is properly cited. 


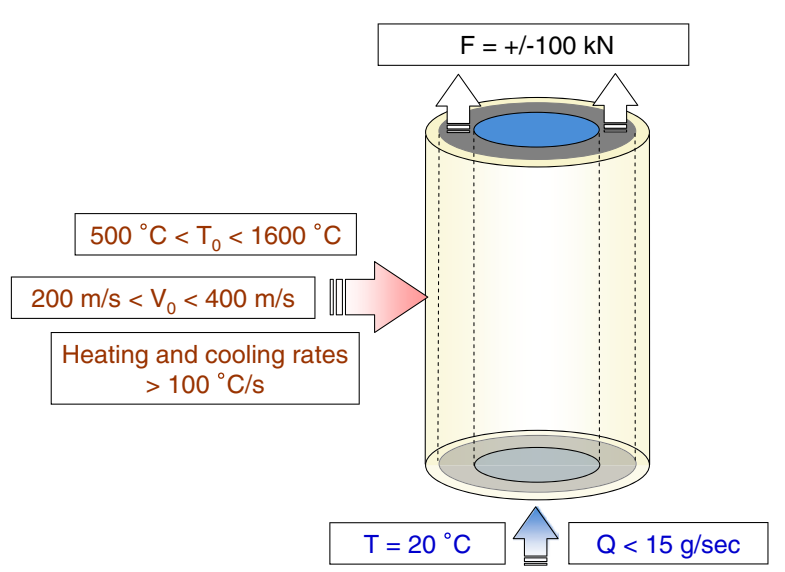

Figure 2. Testing conditions of MAATRE test bench.

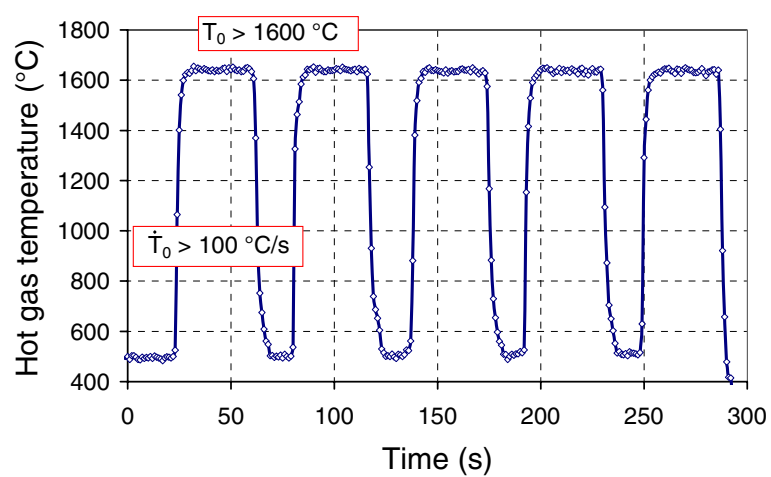

Figure 3. Example of cyclic thermal solicitation performed with the MAATRE test bench.

a creep frame and they could be internally cooled by compressed air.

Monitoring and control of all this equipment parameters (gas and sample temperatures, gas flow, cooling flow and temperatures, sample displacements, sample's applied load ...) as well as security management are ensured using a central computer. The testing conditions MAATRE test bench is able to generate are presented in the Fig. 2 .

It is possible to obtain a gas flow temperature $\mathrm{T}_{0}$ controlled in the $500-1600{ }^{\circ} \mathrm{C}$ range and the hot gas velocity $\mathrm{V}_{0}$ can reach $400 \mathrm{~m} / \mathrm{s}$ at the maximal thermal power of the burner. The heating/cooling rates can be as high as $100^{\circ} \mathrm{C} / \mathrm{s}$. A specific burner with a thermal power of $580 \mathrm{~kW}$ has been design and integrated. As shown in Fig. 3, the test bench is able to supply thermal cycling with the above mentioned temperature and heating/cooling rates.

The mechanical loading, during the tests presented in this article, was applied with a creep testing machine using dead weights. An illustration of the test bench equipped with this creep testing machine is presented in the Fig. 4.

\section{Associated metrology}

A specific metrology has been developed for both the sample's displacement and temperature measurements to perform accurate interpretations of the tests.

During the subsequently presented tests, the temperature of the sample was measured with a spot welded $S$ type

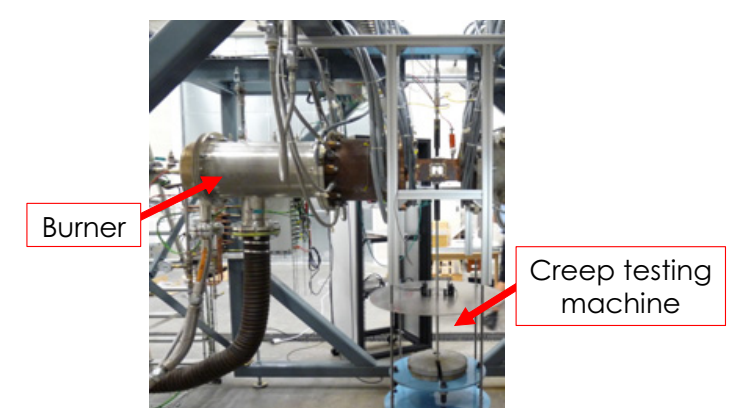

Figure 4. MAATRE test bench equipped with the creep testing machine.

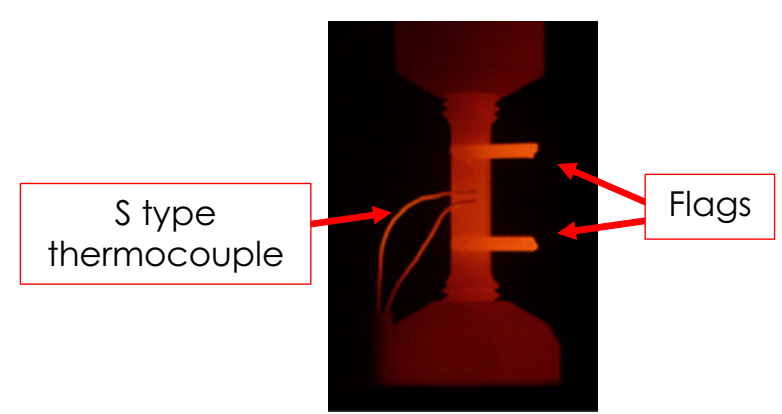

Figure 5. Sample equipped with a spot welded thermocouple and two flags during a non-isothermal creep test.

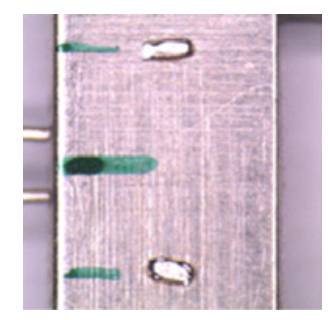

a.

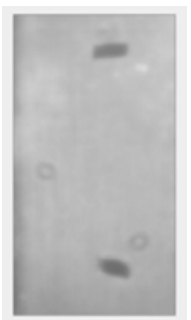

b.

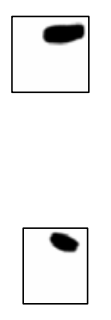

c.
Figure 6. Sample with markers before the test (a) and during the test (b). Post treated images with a Python script (c).

thermocouple. The diameter of this thermocouple has to be big enough to ensure a sufficient mechanical resistance to the aerothermal drag generated by hot gas flow and small enough to avoid thermal perturbations from the thermocouple wire. A $0.35 \mathrm{~mm}$ in diameter thermocouple has been used. The combustion in the burner section has been directly controlled using a close loop using this temperature measurement. The accuracy of this class 1 thermocouple is $+/-1{ }^{\circ} \mathrm{C}$ in the range $0-1000^{\circ} \mathrm{C}$ and $+/-[1+0.003(\mathrm{~T}-1100)]$ in the range $1100-1600^{\circ} \mathrm{C}$.

Two different methods were used to measure the total strain of the sample. On the one hand, an optical micrometer was used to follow the displacement of flags welded on the sample as illustrated in Fig. 5.

On the other hand, a strain measurement method based on markers tracking has been implemented. As it can be observed in Fig. 6, those markers are small wires welded on the sample surface which generate a sufficient optical contrast during the tests.

To track the markers position, a python script developed at the Institut Pprime was used to locate the 


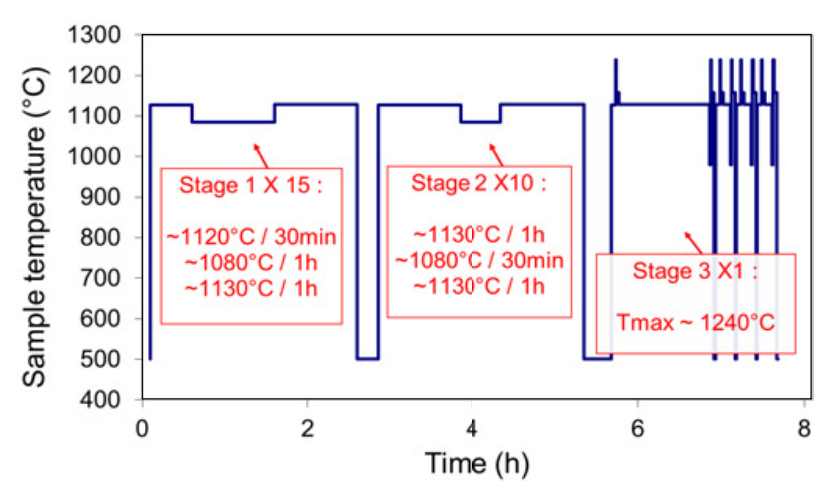

Figure 7. Testing conditions for the $150 \mathrm{~h}$ test.

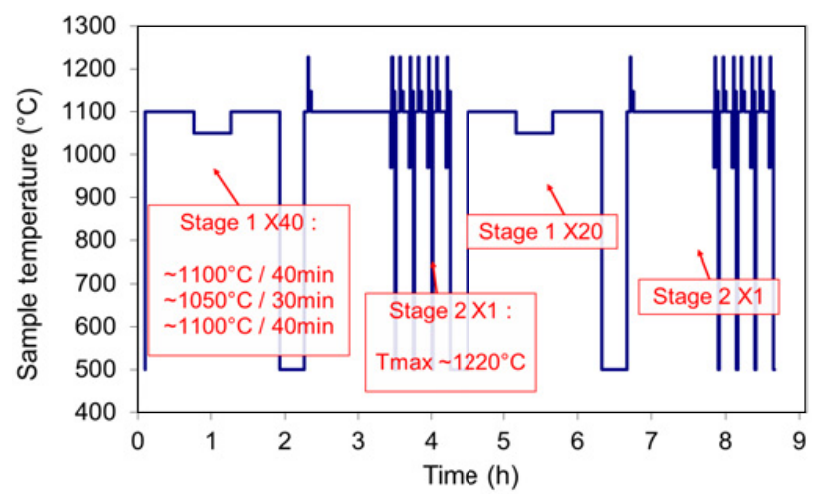

Figure 8. Testing conditions for the ASMET test.

markers and to find their centroid position from pictures taken with a camera.

The strength applied to the sample was also continuously measured using a $5 \mathrm{kN}$ load cell.

\section{Testing conditions}

Two kinds of engine tests were performed, namely a "150 h" and "ASMET" (Accelerated Simulated Mission Endurance Testing). Those tests are composed of different stages. The stages can be divided in long temperature steps or divided in successive temperature peaks. The detail of those testing conditions is presented in the Figs. 7 and 8 respectively.

A tensile stress is applied to the material during the test. It is here worth mentioning that overheatings around 1220 and $1240{ }^{\circ} \mathrm{C}$ are very close to the $\gamma^{\prime}$-solvus $\left(\mathrm{T}_{\text {solvus }}=\right.$ $1265^{\circ} \mathrm{C}$ ) of the alloy used for this study, namely, the first generation MC2 alloy [3,5].

\section{Experimental results}

\section{1. $150 \mathrm{~h}$ test}

The results obtained during the $150 \mathrm{~h}$ test are presented in Fig. 9. This figure shows the evolutions of the sample's temperature and total strain measured along the gage length. The sample did not break at the end of the test.

The temperature pike observed in this figure after $\sim 75 \mathrm{~h}$ is an artefact due to a thermocouple failure.

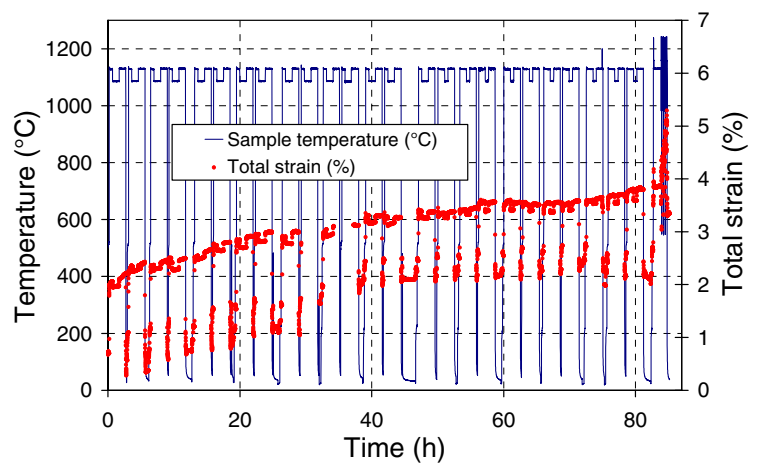

Figure 9. Evolutions of the sample's temperature (in blue, continuous line) and total strain (in red, dotted line) as a function of time for the $150 \mathrm{~h}$ test.

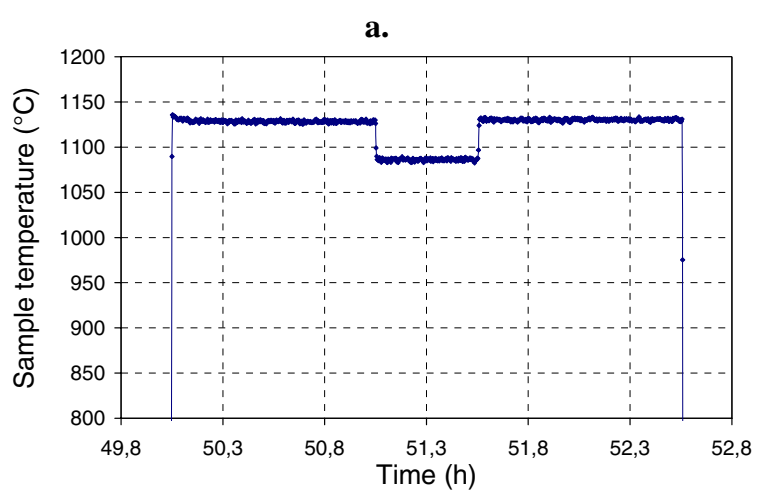

b.

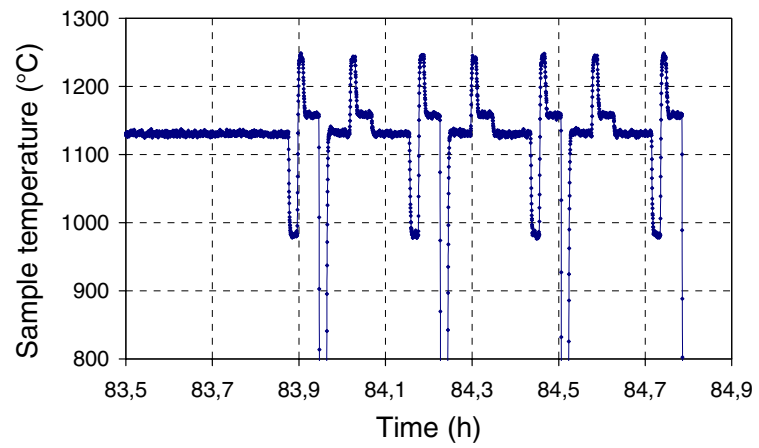

Figure 10. Zooms on the evolution of the sample temperature during the $150 \mathrm{~h}$ test during stage 2 (a) and during stage 3 (b).

During this test, it was possible to reproduce in a very nice way the required thermal loading. Indeed, higher magnifications of one cycle of stage 2 and on the final thermal cycling stage show a very good metal temperature control, as observed in Figs. 10a and 10b respectively.

From the measured total strain and temperature, it is possible to calculate the plastic strain using the temperature dependence of MC2 alloy Young's modulus and thermal expansion coefficient. Indeed, we have:

$$
\varepsilon_{\text {plast }}=\varepsilon_{\text {tot }}-\varepsilon_{\text {elast }}-\varepsilon_{\text {th }}
$$

With, $\varepsilon_{\text {plast }}$ the plastic strain, $\varepsilon_{\text {tot }}$ the measured total strain, $\varepsilon_{\text {elast }}$ the elastic strain $\varepsilon_{\text {th }}$ the thermal strain. 


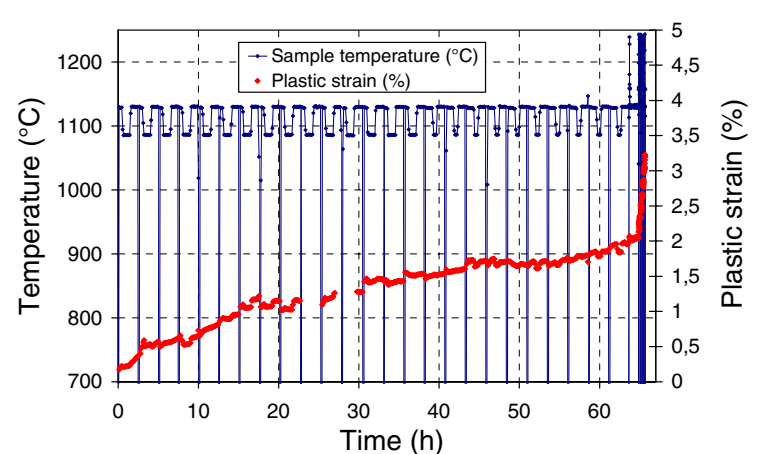

Figure 11. Evolution of plastic strain and sample temperature as a function of time.

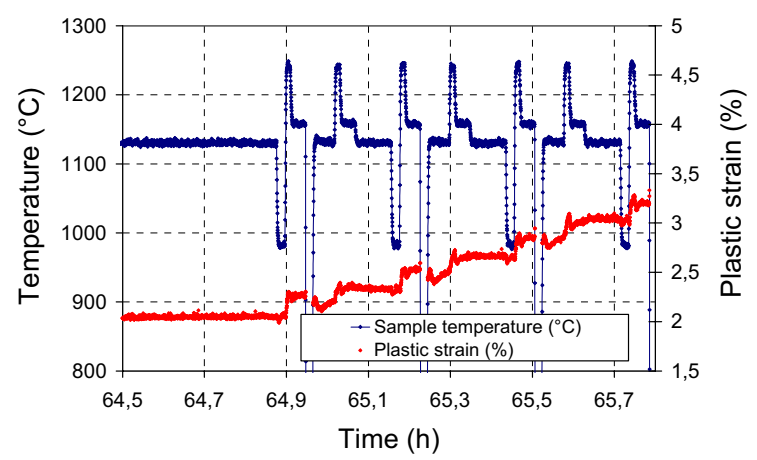

Figure 12. Evolution of the plastic strain and sample temperature as a function of time during the end of the stage 3 .

$\varepsilon_{\text {th }}$ and $\varepsilon_{\text {elast }}$ expressions are:

$$
\begin{aligned}
\varepsilon_{t h} & =\alpha(T) \times\left(T-T_{0}\right) \\
\varepsilon_{\text {elast }} & =E(T) \times \sigma .
\end{aligned}
$$

With, $\alpha(\mathrm{T})$ the coefficient of thermal expansion as a function of temperature, $\mathrm{T}_{0}$ the initial temperature of the sample, E(T) the Young's modulus along a [001] crystallographic orientation and $\sigma$ the applied tensile stress.

The evolutions of calculated plastic strain and measured temperature as a function of time are given in Fig. 11. Under such conditions of strain measurements for a sample loaded under the impact of a gas flow, it can be considered that creep strain measurement is very satisfying. It can be observed in this figure a progressive decrease of the creep rate in the two first stages, and, as expected, a step increase of the creep rate during the last stage containing the overheatings.

This fast increase in strain rate can be observed in a better way in Fig. 12. Each temperature peaks involves a fast creep strain jump. It also appears that the plastic strain seems to decrease during the very fast thermal increases from room temperature to more than $1100^{\circ} \mathrm{C}$. This is an artefact due to the fact that at those particular moments the thermal homogeneity is not achieved in the sample, leading to an overestimation of the actual thermal strain.

SEM observations have been performed after this $150 \mathrm{~h}$ engine-like test. As shown in Fig. 13, the $\gamma^{\prime}$ precipitates have undergone the so-called $\gamma^{\prime}$-rafting. Moreover we can notice that the complex thermal cycling performed during the third stage generated a thin tertiary precipitation [6]. a)

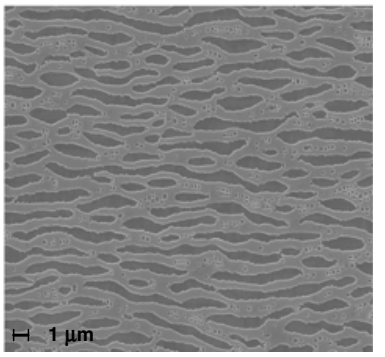

b)

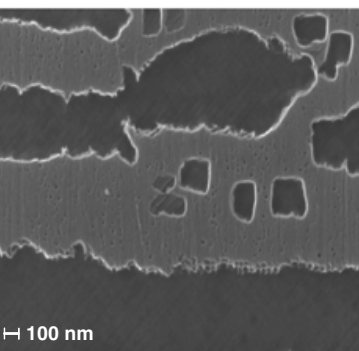

c)

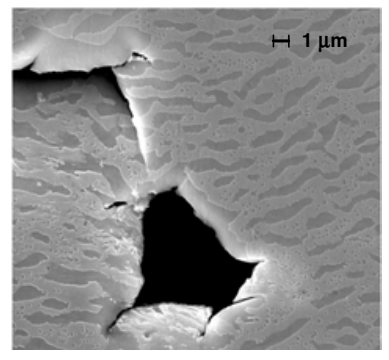

Figure 13. SEM micrographs showing the $\gamma^{\prime}$-rafting after the $150 \mathrm{~h}$ test in the primary dendrites arms (a) the precipitation of tertiary $\gamma^{\prime}$ precipitates (b) and the development of microcracks from casting pores in an interdendritic spacing close to the sample's surface (c).

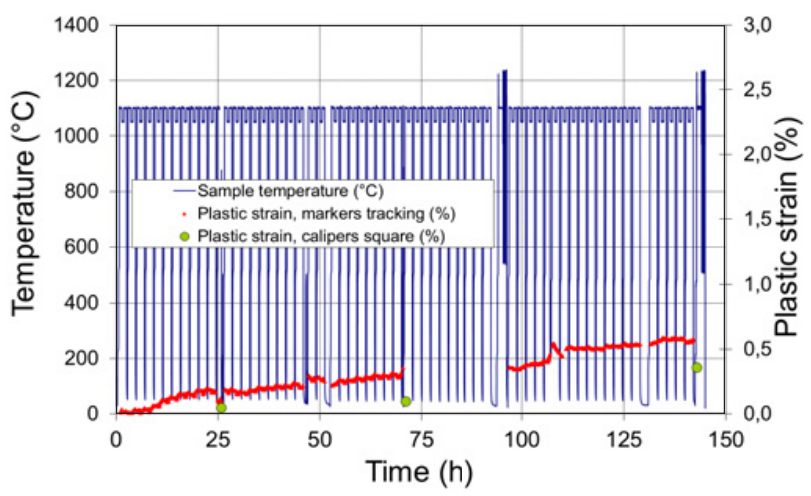

Figure 14. Evolutions of the sample's temperature (in blue, continuous line) and total strain (in red, dotted line) as a function of time for the ASMET test.

Finally, first evidences of the development of damage are observed in Fig. 13c, with the nucleation of cracks for casting pores, close to the sample's surface.

\subsection{ASMET test}

The results obtained during the ASMET test are presented in Fig. 14. The evolution of plastic strain is here calculated from total strain measured with optical markers tracking method. 
a)
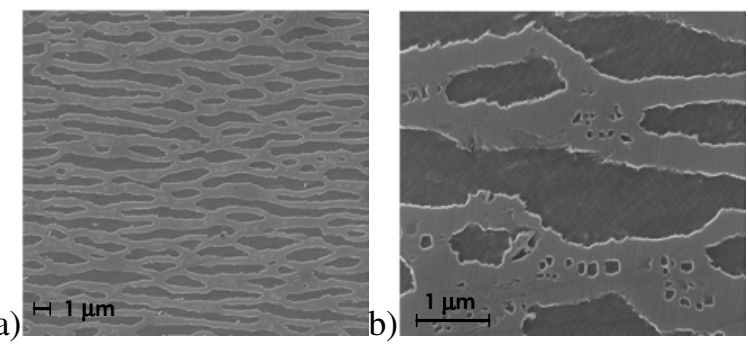

Figure 15. SEM micrographs showing the $\gamma^{\prime}$-rafting after the $150 \mathrm{~h}$ test in the primary dendrites arms (a) the precipitation of tertiary $\gamma^{\prime}$ precipitates $(b)$.

The absence of strain measurement between 75 and $100 \mathrm{~h}$ is due to a computer data overflow. Moreover, strain measurements was not possible during the overheatings, due to a too large radiation of the sample, avoiding any possibility of markers localization. The optical markers tracking method seemed however to give good results during the 75 first hours, with a good correspondence with a mechanical micrometer measurement after sample removal from the testing section. Indeed, the sample had to be removed from the test bench because of a thermocouple failure.

Microstructure observations after this test are presented in Fig. 15. As for the $150 \mathrm{~h}$ test, the microstructure exhibits rafted $\gamma^{\prime}$ precipitates and thin third precipitates due to the complex thermal cycles. However, no signs of damage such as cracks nearby pores were found, in good agreement with the rather low creep strain at the end of the test $(\sim 0.5 \%)$.

\section{Comparison with Polystar model}

A new crystal plasticity model called Polystar [3,4] has been used to simulate the two previous tests. Polystar was particularly developed for complex non-isothermal loadings. This model takes into account microstructural changes which can occur in the material such as $\gamma^{\prime}$ precipitation/dissolution and dislocation recovery processes induced by the temperature history seen by the material, especially close to the $\gamma^{\prime}$ solvus temperature [7]. The model was calibrated using isothermal and nonisothermal creep tests performed on MC2 samples having a stress axis close to the [001] crystallographic direction (deviation less than 8 degrees). The real testing temperatures and stresses recorded during the $150 \mathrm{~h}$ and ASMET tests have been used as input data for the simulation.

As shown in Fig. 16, the Polystar model provides a very good description of the creep strain for the $150 \mathrm{~h}$ test. The prediction of the first 40 hours of the test is very close to the creep strain measurements. From 40 to 80 hours the calculated creep rates seem to be smaller than the experimental ones, this difference leading to an underestimation of the plastic strain of around 30\% after 80 hours. In opposition, the model overestimates the strain evolution during the last part of the test composed of the overheatings. As we can see in Fig. 17, the model is able to reproduce the strain jumps recorded during the test, but the calculated jumps' amplitude is increasing while

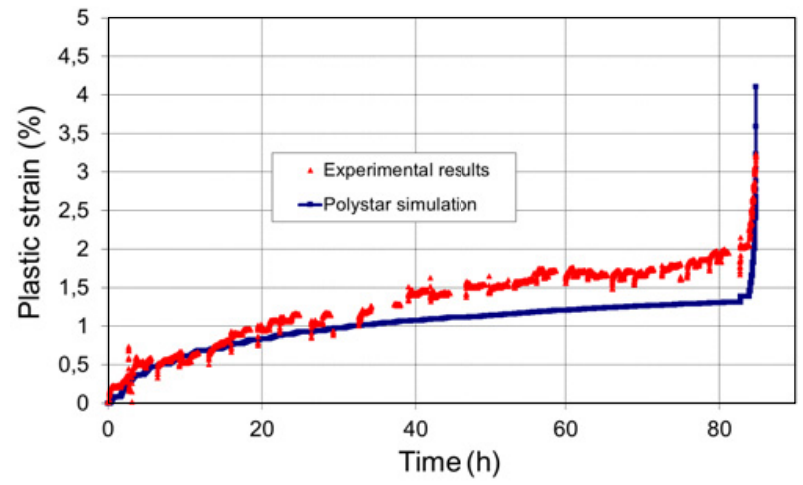

Figure 16. Comparison between the experimental elongation and the Polystar simulation for the $150 \mathrm{~h}$ engine-like test.

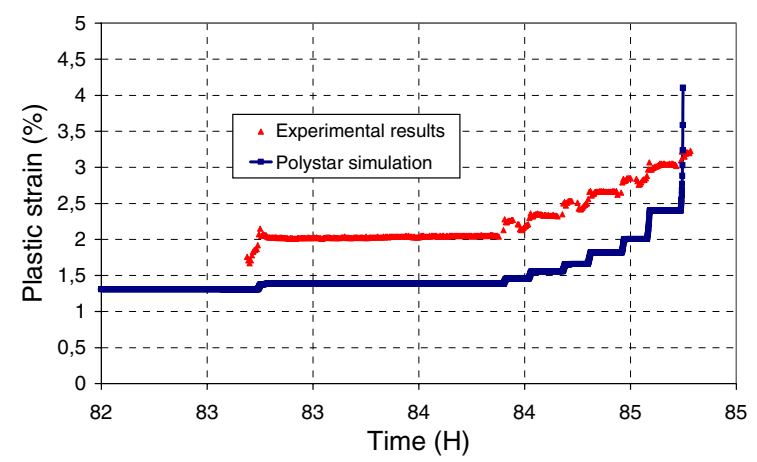

Figure 17. Comparison between the experimental elongation and the Polystar simulation for the $150 \mathrm{~h}$ engine-like test during the last stage.

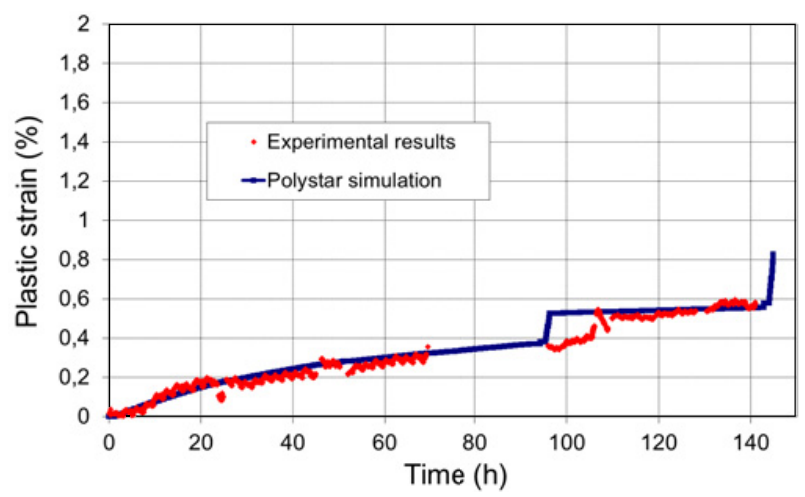

Figure 18. Comparison between the experimental elongation and the Polystar simulation for the ASMET engine-like test.

experimentally, the amplitude of the creep strain jumps remain almost constant. According to the simulation, the material should have failed few minutes before the end of the test. Even if the sample did not break during the test, observed microstructures showed signs of damage development.

The same work as been performed for the ASMET test, as it can be observed in Fig. 18. The Polystar results are in very good agreement with the experimental ones during the first part of the test. As in the $150 \mathrm{~h}$ results, the calculated creep rates seem to be smaller than the experimental ones in the lowest temperature ranges and bigger in the highest temperature ranges. 
Those two simulations show the Polystar capabilities in estimating the plastic strain in those complex tests representative of in-service thermomechanical conditions. The model seems to be very accurate in the lowest temperature of testing but can overestimate the strains in the highest temperature ranges. It can come from a poorer precision in the model calibration at very high temperature levels. Nevertheless, this model with its additional internal variable is the only one able to capture complex microstructural phenomena such as dissolution/precipitation of strengthening particles, dislocation recovery processes and their impact of the mechanical behavior. Under very complex conditions such as the ones presented in this article, this model performs better than any other model where the temperature dependence is only taken into account through the temperature dependence of the material's coefficients $[7,8]$.

\section{Conclusion}

Two non-isothermal creep tests have been performed under complex thermal cycling conditions representative of real conditions seen in high pressure turbine blades of helicopter engines during certification. Those tests have been performed under a hot gases environment thanks to the development of a new burner rig called MAATRE. Two different experimental techniques have been designed to measure the plastic strain of the material during the test. Those experimental results have been compared with a simulation using the specific crystal plasticity mode Polystar. The simulations gave rather satisfying results considering the complexity of the experiments. The capabilities of the MAATRE test bench in reproducing complex thermomechanical loading paths could hence be used in a near future as a mean of validation of lifing methodologies.

The authors are grateful to SARGI S.A. for their help and efficiency in the design of the unpreceding burner used in MAATRE. CPER and FEDER (Poitou-Charentes Region, Vienne Department, European Community, Poitiers Agglomeration and French Education and Research Ministry) financial supports are gratefully acknowledged.

\section{References}

[1] R.C. Reed, The Superalloys - Fundamentals and applications, (Cambridge University press, 2006)

[2] T.M. Pollock, S. Tin, J. Prop. Pow. 22, 361 (2006)

[3] J. Cormier, G. Cailletaud, Mat. Sci. Eng. A527, 6300 (2010)

[4] J. Ghighi, J. Cormier, E. Ostoja-Kuczynski, J. Mendez, G. Cailletaud, F. Azzouz, Tech. Mech. 32, 205 (2011)

[5] J. Cormier, X. Milhet, J. Mendez, F. Vogel, Proceedings of the $11^{\text {th }}$ International conference on Superalloys, Superalloys 2008, 941 (2008)

[6] J.-B. le Graverend, J. Cormier, M. Jouiad, F. Gallerneau, P. Paulmier, F. Hamon, Mat. Sci. Eng. A527, 5295 (2010)

[7] J.-B. le Graverend, L. Dirand, A. Jacques, J. Cormier, O. Ferry, T. Schenk, F. Gallerneau, S. Kruch, J. Mendez, Met. Mat. Trans. 43A, 3946 (2012)

[8] J.-B. le Graverend, J. Cormier, F. Gallerneau, P. Villechaise, S. Kruch, J. Mendez, Int. J. of Plast. 59, 55 (2014) 